\title{
硝子中の硼酸の定量分光分析に就て (第一報)
}

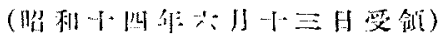

原州健三

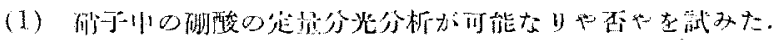

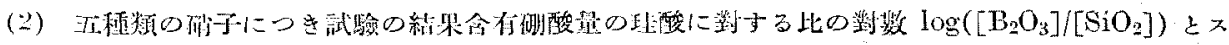

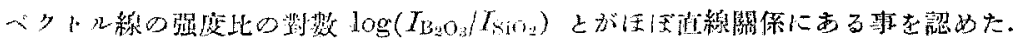

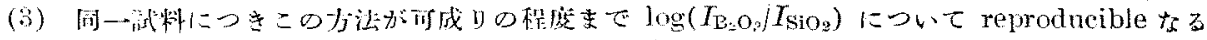
J゙证いた。

\section{序言}

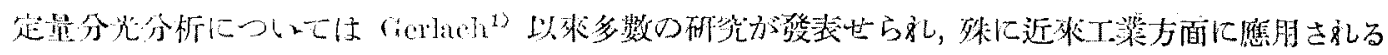

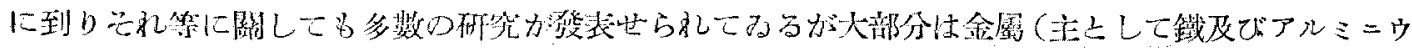

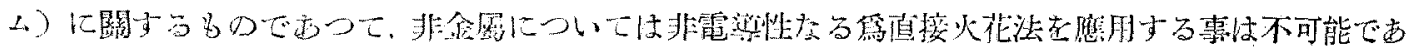

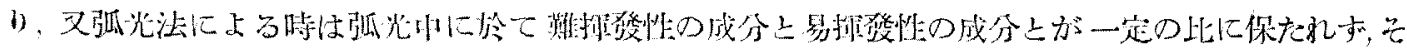

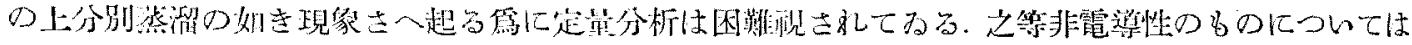

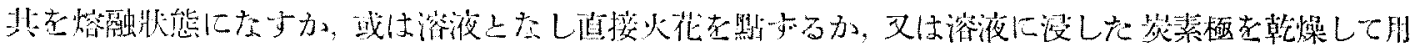

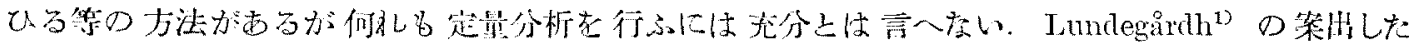

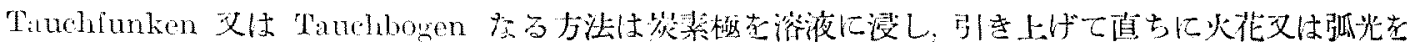

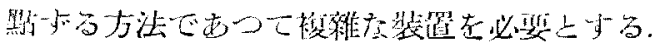

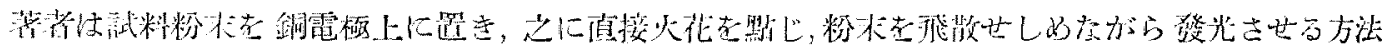

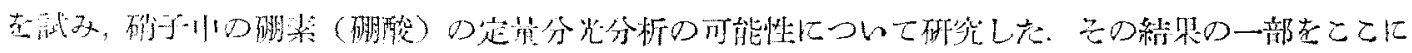

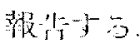

\section{實驗}

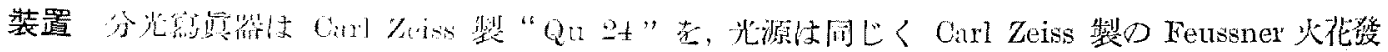

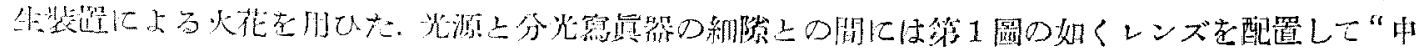

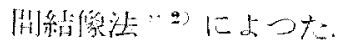

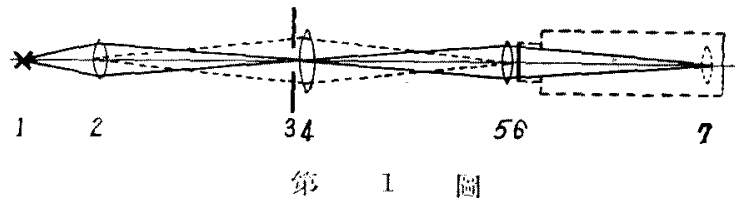

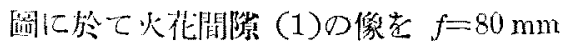
の水晶レンズ(2)によつてスクリーン（3） の上に約? 僧に結像せしぬる。このスタリ ーンにあけら礼た矩形の大によつて火花像

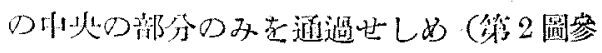

1) Walter Gerlach nud Engen Schweitzer, "Die Chemische Enissionsspelstralanalyse" I Teil,

198\%. Walter Gerlach und Werner Gerlach, " " " " " II Teil, 1933.

II. Lundegardh, "Jie quantitative Spektralanalyse der Elemente" Jena, 1929.

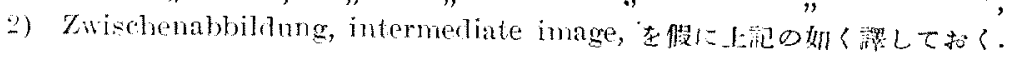

", II Teil Jena, 1934. 


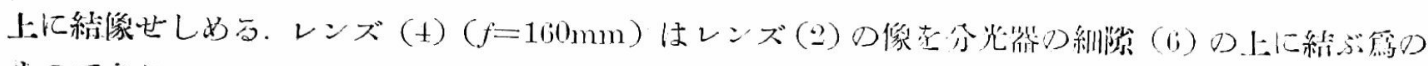
为のでする。

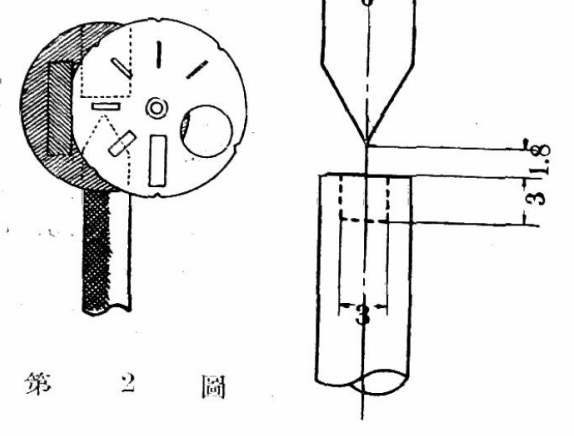

鸽 3 渵

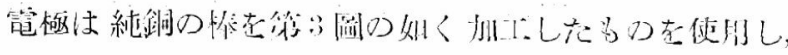

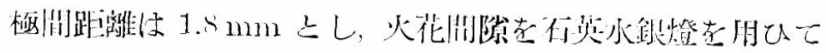

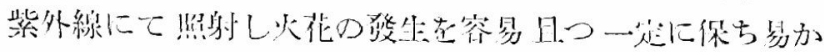
らしめた。

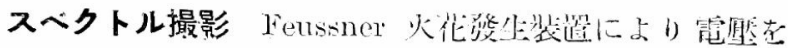

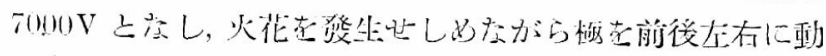

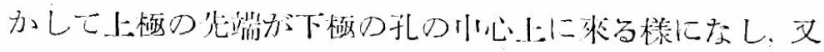

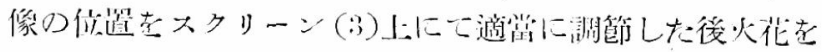

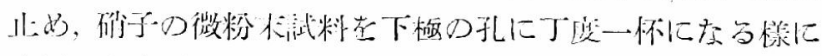

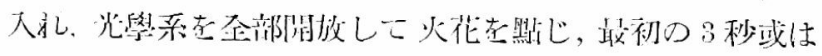

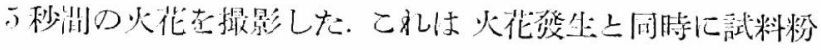

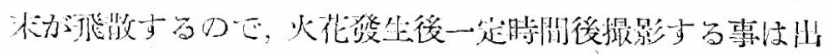
來なかつた䉆である。この方法古假に“粉北火花法 Powder spark method”上名づけておく.同一

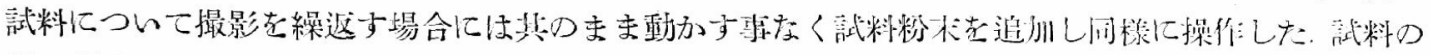

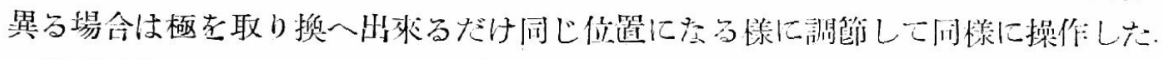

使用乾板 フジ，亦オクロ一ム乾板

現 像 Eastman D $76 \mathrm{~d}, 18^{\circ} \mathrm{C}, 15$ 分

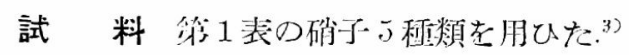

第 1 效

\begin{tabular}{|c|c|c|c|c|c|}
\hline 試料 & $A-1$ & $A-2$ & $A-3$ & $A-4$ & $1-5$ \\
\hline $\mathrm{SiO}_{2}$ & 67.30 & 49.85 & 64.56 & 46.11 & 39.55 \\
\hline $\mathrm{B}_{2} \mathrm{O}_{3}$ & 11.00 & 6.13 & 3.00 & 3.68 & 13.50 \\
\hline $\mathrm{CaO}$ & - & - & - & - & - \\
\hline $\mathrm{BaO}$ & $\triangle$ & 0 & 0 & 0 & 0 \\
\hline $\mathrm{PbO}$ & - & $\Delta$ & - & $\Delta$ & - \\
\hline $\operatorname{ZnO}$ & - & 0 & $\Delta$ & 0 & - \\
\hline $\mathrm{K}_{2} \mathrm{O}$ & 0 & 0 & $0^{\circ}$ & 0 & - \\
\hline$>a, 0$ & 0 & 0 & 0 & $\Delta$ & - \\
\hline $\mathrm{As}_{2} \mathrm{O}_{3}$ & $\Delta$ & $\Delta$ & $\Delta$ & $\Delta$ & $\triangle$ \\
\hline$\frac{\mathrm{B}_{22} \mathrm{O}_{3}}{\mathrm{SiO}_{2}} \%$ & 16.34 & 12.30 & 4.65 & 7.98 & 34.13 \\
\hline
\end{tabular}

○稍々多量会们す

$\triangle$ 微量会行士

一合你せず

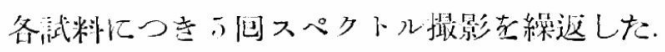

符 2 丧

Kayser による

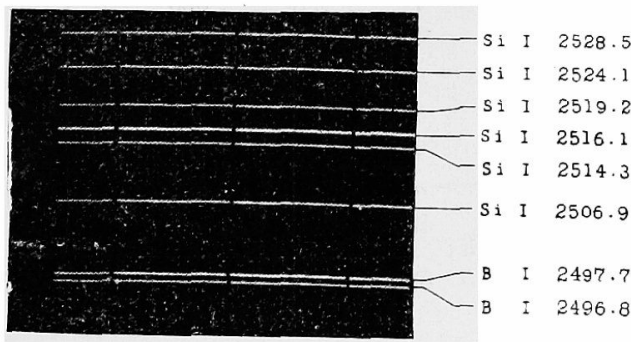

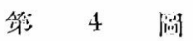

\begin{tabular}{|c|c|c|c|c|}
\hline $\mathrm{Si}$ & $I$ & 2528.5 & $10 \mathrm{R}$ & 111 \\
\hline$\Delta i$ & I & 2524.1 & $10 \mathrm{R}$ & $1 i$ \\
\hline $\mathrm{Si}$ & $I$ & 2519.2 & $8 \mathrm{R}$ & 5 \\
\hline $\mathrm{Si}$ & $I$ & 2516.1 & $10 \mathrm{R}$ & 11 \\
\hline $\mathrm{si}$ & I & 2514.3 & $8 \mathrm{H}$ & $\therefore$ \\
\hline Si & I & 2506.9 & $10 \mathrm{Ii}$ & ti \\
\hline l) & & $2+97.7$ & $10 \mathrm{R}$ & $10 \mathrm{~K}$ \\
\hline B & & 2496.8 & $y \mathrm{R}$ & 9) $\mathrm{R}$ \\
\hline
\end{tabular}

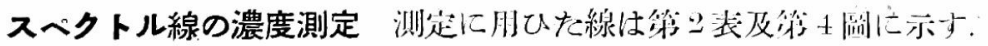

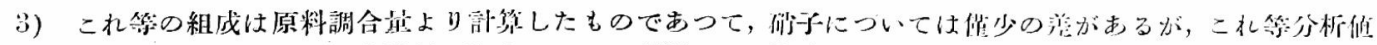

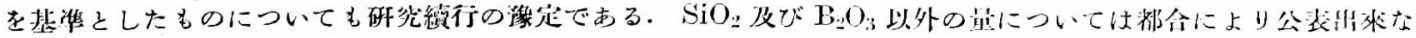

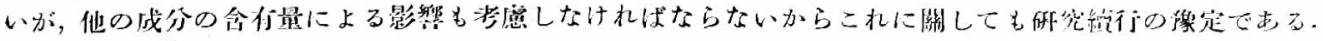




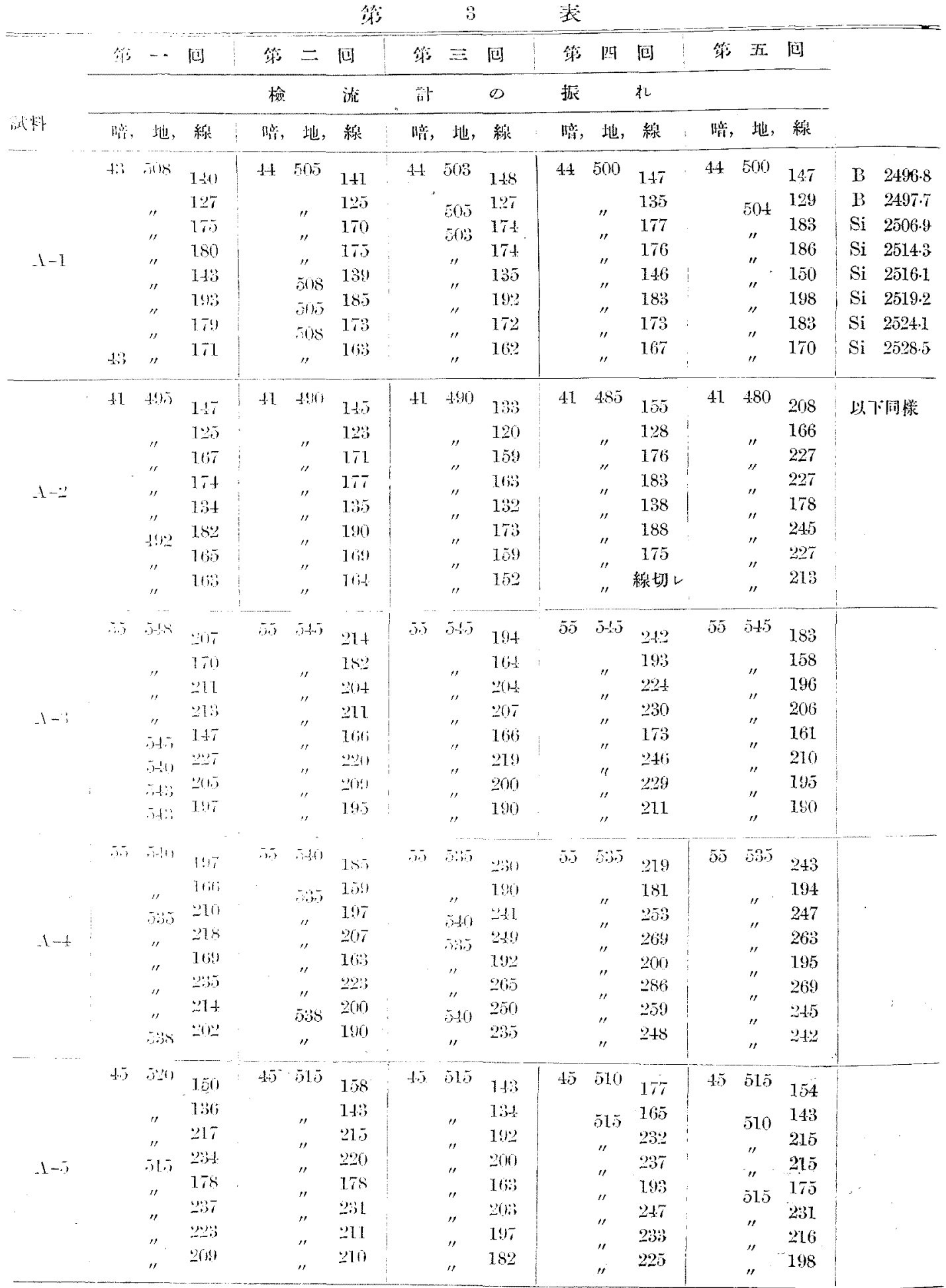




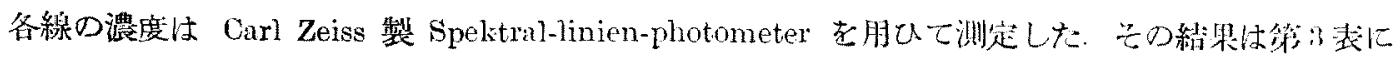

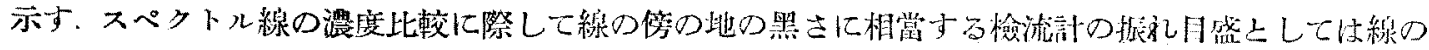

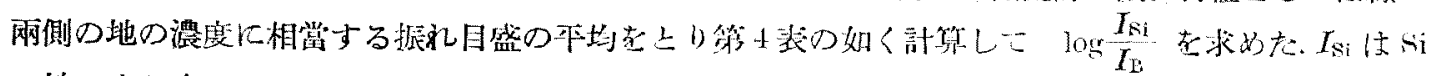
の線の光强度， $I_{\mathrm{B}}$ は $\mathrm{B}$ の線の光强度走方.

佻 4 非

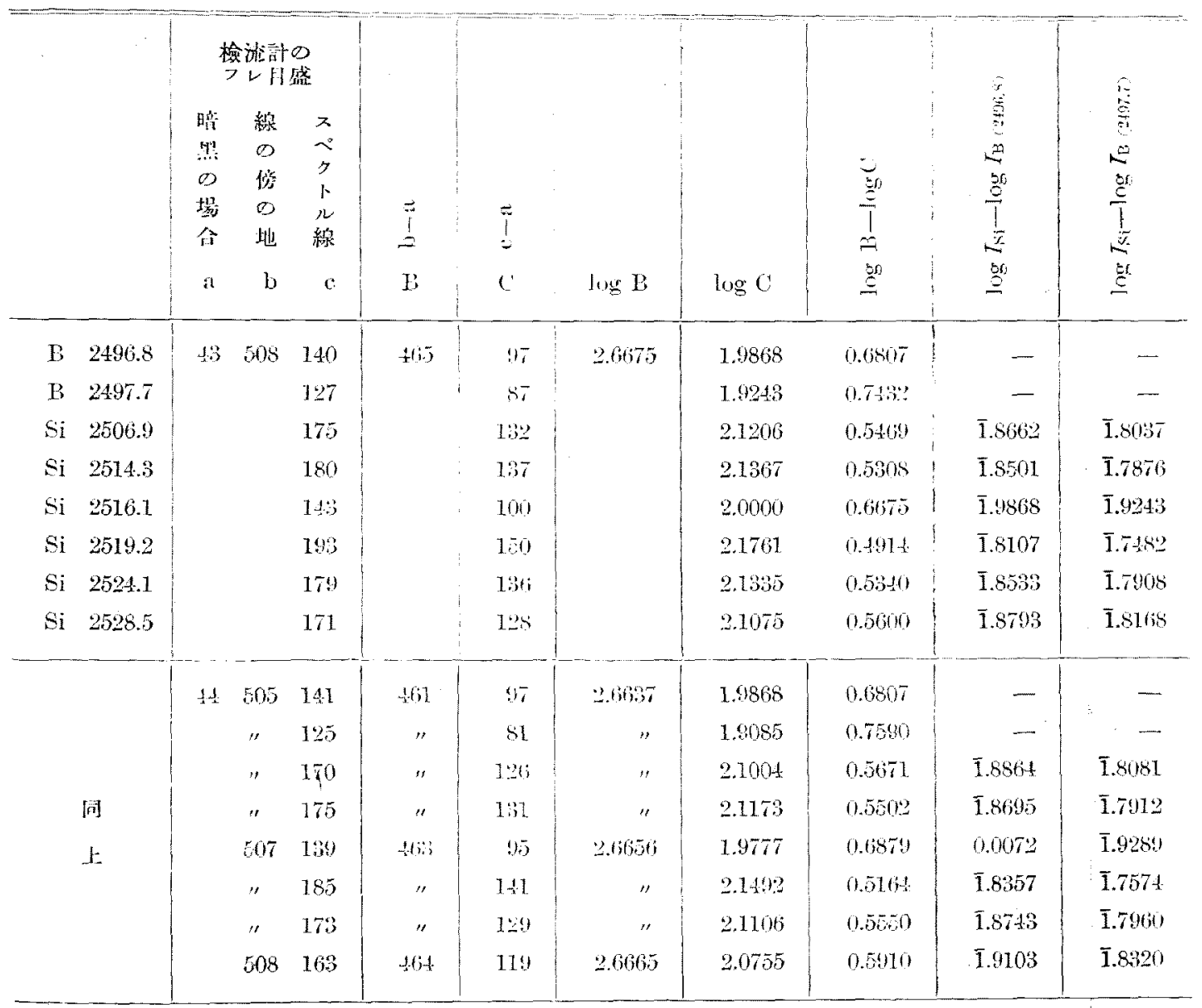

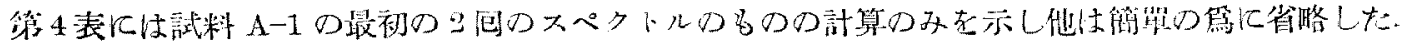

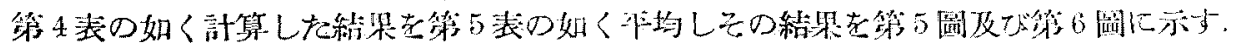

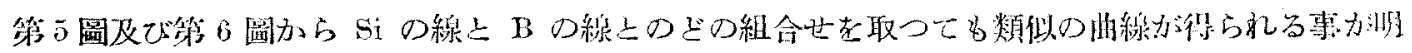

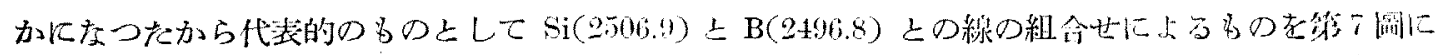

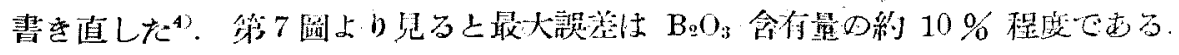

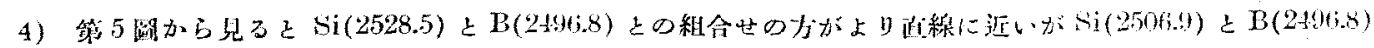
のカが近接してるるからこの少を棎朋した。 


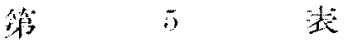

\begin{tabular}{|c|c|c|c|c|c|c|c|c|c|c|c|c|}
\hline \multirow{2}{*}{ 料 } & \multicolumn{2}{|c|}{ 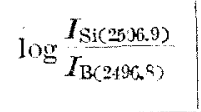 } & \multicolumn{2}{|c|}{$\log \frac{\left.I_{\mathrm{SC}}=014.3\right)}{I_{\mathrm{B}(2496.83}}$} & \multicolumn{2}{|c|}{$\log \frac{I_{\mathrm{St}(2516,1)}}{I_{\mathrm{B}(2406,8)}}$} & \multicolumn{2}{|c|}{$\log \frac{T_{S i(2519.2)}}{I_{13(2104)}}$} & \multicolumn{2}{|c|}{$\log \frac{I_{\mathrm{Si}(524.1)}}{I_{13(2496.5)}}$} & \multicolumn{2}{|c|}{$\log \frac{I_{\mathrm{Si}}(29.94 .5)}{I_{\mathrm{B}(2.990 .9)^{\prime}}}$} \\
\hline & $\begin{array}{r}\overline{1} .866 \\
886 \\
904 \\
889 \\
874 \\
\end{array}$ & $\begin{array}{r}1.884 \\
0.716\end{array}$ & $\begin{array}{r}1.851 \\
870 \\
603 \\
891 \\
861\end{array}$ & $\begin{array}{r}1.876 \\
0.12 .4\end{array}$ & $\begin{array}{r}\overline{1} .987 \\
0.007 \\
058 \\
004 \\
1.991\end{array}$ & $\begin{array}{c}0.009 \\
\overline{1} .00 t\end{array}$ & $\begin{array}{r}1.811 \\
836 \\
847 \\
874 \\
8.7\end{array}$ & $\begin{array}{r}\overline{1} .839 \\
0.161\end{array}$ & $\begin{array}{r}\overline{1} .853 \\
874 \\
910 \\
902 \\
874\end{array}$ & $\begin{array}{r}\overline{1} .883 \\
0.117\end{array}$ & $\begin{array}{r}1.879 \\
909 \\
945 \\
923 \\
916\end{array}$ & $\begin{array}{r}\overline{1} .914 \\
0.08 B\end{array}$ \\
\hline$A-2$ & $\begin{array}{r}1.925 \\
903 \\
842 \\
926 \\
958\end{array}$ & $\begin{array}{r}\overline{1} .920 \\
0.080\end{array}$ & $\begin{array}{r}1.901 \\
881 \\
8.7 \\
605 \\
958\end{array}$ & $\begin{array}{r}\overline{1} .904 \\
0.099\end{array}$ & $\begin{array}{l}0.057 \\
043 \\
005 \\
070 \\
086\end{array}$ & $\begin{array}{r}0.052 \\
7.948\end{array}$ & $\begin{array}{r}1.875 \\
844 \\
860 \\
840 \\
913\end{array}$ & $\begin{array}{r}\overline{1} .873 \\
0.1 \therefore\end{array}$ & $\begin{array}{r}1.929 \\
910 \\
892 \\
930 \\
953\end{array}$ & $\begin{array}{r}\overline{1} .923 \\
0.07 \%\end{array}$ & $\begin{array}{r}1.936 \\
926 \\
919 \\
987\end{array}$ & $\begin{array}{r}\overrightarrow{1} .942 \\
0.058\end{array}$ \\
\hline $1-3$ & $\begin{array}{l}\overline{1} .984 \\
0.028 \\
1.960 \\
0.044 \\
\overline{1} .954 \\
\end{array}$ & $\begin{array}{r}1.998 \\
11.00 \%\end{array}$ & $\begin{array}{l}\overline{1} .982 \\
0.008 \\
\overline{1} .961 \\
0.029 \\
\overline{1} .928 \\
\end{array}$ & $\begin{array}{r}1.982 \\
0.018 \\
\end{array}$ & $\begin{array}{r}0.105 \\
156 \\
098 \\
120 \\
082\end{array}$ & $\begin{array}{c}0.112 \\
1.889\end{array}$ & $\begin{array}{c}1.94: 2 \\
984 \\
982 \\
091 \\
917\end{array}$ & $\begin{array}{r}1.963 \\
0.037\end{array}$ & $\begin{array}{r}0.000 \\
014 \\
\overline{1} .981 \\
0.031 \\
\overline{1.961} \\
\end{array}$ & $\begin{array}{r}1.997 \\
0.003\end{array}$ & $\begin{array}{r}0.025 \\
0.055 \\
018 \\
079 \\
1.977\end{array}$ & $\begin{array}{r}0.030 \\
\overline{1} .9 \% 0\end{array}$ \\
\hline $1-1$ & $\begin{array}{r}.962 \\
974 \\
918 \\
957 \\
999\end{array}$ & $\begin{array}{r}\overrightarrow{1} .960 \\
0.0 .40\end{array}$ & $\begin{array}{r}1.936 \\
953 \\
884 \\
928 \\
055\end{array}$ & $\begin{array}{r}1.931 \\
0.069\end{array}$ & $\begin{array}{r}0.091 \\
10 \% \\
053 \\
076 \\
028\end{array}$ & $\begin{array}{c}0.060 \\
1.9 .70\end{array}$ & $\begin{array}{c}1.893 \\
416 \\
851 \\
881 \\
943\end{array}$ & $\begin{array}{r}\overline{1} .877 \\
0.123\end{array}$ & $\begin{array}{r}\overline{1} .918 \\
951 \\
.905 \\
950 \\
995\end{array}$ & $\begin{array}{r}\overline{1} .950 \\
0.050\end{array}$ & $\begin{array}{r}1.983 \\
988 \\
929 \\
982 \\
0.002\end{array}$ & $\begin{array}{r}1.977 \\
0.023\end{array}$ \\
\hline$A-\overline{5}$ & $\begin{array}{r}1.789 \\
823 \\
824 \\
853 \\
802\end{array}$ & $\begin{array}{r}.818 \\
0.18\end{array}$ & $\begin{array}{r}1.743 \\
810 \\
801 \\
842 \\
802\end{array}$ & $\begin{array}{r}1.800 \\
0.200\end{array}$ & $\begin{array}{r}1.893 \\
929 \\
919 \\
955 \\
922\end{array}$ & $\begin{array}{r}1.924 \\
0.0 \% 6\end{array}$ & $\begin{array}{r}7.733 \\
784 \\
763 \\
830 \\
768\end{array}$ & $\begin{array}{r}1.780 \\
0.200\end{array}$ & $\begin{array}{r}1.760 \\
833 \\
809 \\
851 \\
804\end{array}$ & $\begin{array}{r}\overline{1} .813 \\
0.18 \%\end{array}$ & $\begin{array}{r}.802 \\
836 \\
855 \\
870 \\
854\end{array}$ & $\begin{array}{r}1.843 \\
0.15 \%\end{array}$ \\
\hline & $\log _{I_{\mathrm{D}}}$ & 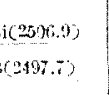 & $\log \frac{I_{3}}{I_{1}}$ & $\frac{(2514.8)}{B(2497.7)}$ & $\log \frac{I}{I}$ & $\frac{S i(2516.1)}{B(2497 . i)}$ & $\log \frac{I}{I}$ & $\frac{(1<(2519.2)}{B(2497.7)}$ & $\log \frac{I_{\mathrm{S}}}{I_{\mathrm{B}}}$ & $\frac{1(2694.1)}{(2497.3)}$ & $\log \frac{I_{\mathrm{S}}}{I_{\mathrm{B}}}$ & $\frac{(2523.5)}{(207.7)}$ \\
\hline$-1-1$ & $\begin{array}{r}1.804 \\
808 \\
805 \\
835 \\
788\end{array}$ & $\begin{array}{r}1.808 \\
0.1 \\
\end{array}$ & $\begin{array}{c}7.788 \\
791 \\
801 \\
838 \\
799\end{array}$ & $\begin{array}{r}\mathbf{1} .800 \\
0.200\end{array}$ & $\begin{array}{r}1.924 \\
924 \\
\$ 159 \\
\$ 50 \\
906\end{array}$ & $\begin{array}{c}\overline{1.934} \\
\text { o. }\end{array}$ & $\begin{array}{r}1.748 \\
767 \\
748 \\
816 \\
714\end{array}$ & $\begin{array}{r}1.763 \\
0.28 \%\end{array}$ & $\begin{array}{r}7.791 \\
796 \\
811 \\
818 \\
788\end{array}$ & $\begin{array}{r}\overline{\mathbf{1}} .807 \\
0.193\end{array}$ & $\begin{array}{r}1.817 \\
831 \\
846 \\
869 \\
831\end{array}$ & $\begin{array}{r}1.839 \\
0.161 \\
\end{array}$ \\
\hline $1-2$ & $\begin{array}{r}1.824 \\
800 \\
826 \\
809 \\
827 \\
\end{array}$ & $\begin{array}{r}1.817 \\
0.13 \\
\end{array}$ & $\begin{array}{c}\overline{1} .8111 \\
7801 \\
811 \\
787 \\
827\end{array}$ & $\begin{array}{r}\overline{1} .801 \\
0.199\end{array}$ & $\begin{array}{c}1.956 \\
941 \\
939 \\
953 \\
960\end{array}$ & $\begin{array}{r}\overline{1} .950 \\
0.050\end{array}$ & $\begin{array}{r}1.74 \\
741 \\
77 \% \\
772 \\
787\end{array}$ & $\begin{array}{r}1.760 \\
0.240\end{array}$ & $\begin{array}{r}1.828 \\
807 \\
826 \\
812 \\
827\end{array}$ & $\begin{array}{r}1.820 \\
0.180\end{array}$ & $\begin{array}{r}1.835 \\
824 \\
852 \\
-\overline{1} \\
861\end{array}$ & $\begin{array}{r}1.834 \\
0.166\end{array}$ \\
\hline$A-3$ & $\begin{array}{r}1.868 \\
981 \\
854 \\
912 \\
864\end{array}$ & $\begin{array}{r}1.886 \\
0.114\end{array}$ & $\begin{array}{r}1.861 \\
811 \\
856 \\
807 \\
834\end{array}$ & $\begin{array}{r}1.872 \\
0.138\end{array}$ & $\begin{array}{l}\overline{1} .984 \\
0.054 \\
\overline{1} .992 \\
0.068 \\
\overline{1} .987\end{array}$ & $\begin{array}{c}0.018 \\
7.98\end{array}$ & $\begin{array}{r}1.821 \\
886 \\
823 \\
809 \\
823\end{array}$ & $\begin{array}{r}1.842 \\
0.158\end{array}$ & $\begin{array}{r}1.879 \\
916 \\
876 \\
899 \\
867\end{array}$ & $\begin{array}{r}\overline{\mathbf{1}} . \mathbf{8 8 7} \\
0.119\end{array}$ & $\begin{array}{r}.904 \\
958 \\
907 \\
947 \\
983 \\
\end{array}$ & $\begin{array}{r}\overline{1} .940 \\
0.060\end{array}$ \\
\hline $1-4$ & $\begin{array}{r}\overline{1} .853 \\
861 \\
804 \\
862 \\
860\end{array}$ & $\begin{array}{r}\overline{\mathbf{1}} .848 \\
0.15 \%\end{array}$ & $\begin{array}{r}1.820 \\
841 \\
770 \\
838 \\
824\end{array}$ & $\begin{array}{r}1.819 \\
0.181\end{array}$ & $\begin{array}{r}\overline{1} .984 \\
989 \\
939 \\
981 \\
997\end{array}$ & $\begin{array}{r}1.978 \\
0.0 ? 2\end{array}$ & $\begin{array}{r}1.786 \\
804 \\
737 \\
780 \\
813\end{array}$ & $\begin{array}{r}1.786 \\
0.914\end{array}$ & $\begin{array}{r}\overline{1} .841 \\
830 \\
791 \\
855 \\
864\end{array}$ & $\begin{array}{r}\mathbf{1} .838 \\
0.16\end{array}$ & $\begin{array}{r}876 \\
875 \\
815 \\
887 \\
871\end{array}$ & $\begin{array}{r}\overline{1} .865 \\
0.135\end{array}$ \\
\hline$A-5$ & $\begin{array}{r}1.724 \\
761 \\
782 \\
809 \\
758\end{array}$ & $\begin{array}{r}1.767 \\
0.9 .7\end{array}$ & $\begin{array}{r}1.681 \\
748 \\
750 \\
798 \\
758\end{array}$ & $\begin{array}{r}\overline{1.749} \\
0.251\end{array}$ & $\begin{array}{r}.831 \\
867 \\
878 \\
911 \\
877\end{array}$ & $\begin{array}{c}\overline{1.873} \\
0.12\end{array}$ & $\begin{array}{r}1.671 \\
722 \\
751 \\
766 \\
724\end{array}$ & $\begin{array}{r}1.729 \\
0.271\end{array}$ & $\begin{array}{r}1.704 \\
771 \\
768 \\
807 \\
760\end{array}$ & $\begin{array}{r}\overline{\mathbf{1}} .762 \\
0.298\end{array}$ & $\begin{array}{r}.740 \\
774 \\
813 \\
826 \\
808\end{array}$ & $\begin{array}{r}\overline{1.792} \\
0.208\end{array}$ \\
\hline
\end{tabular}

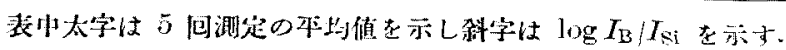




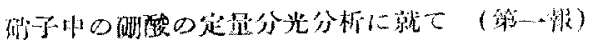

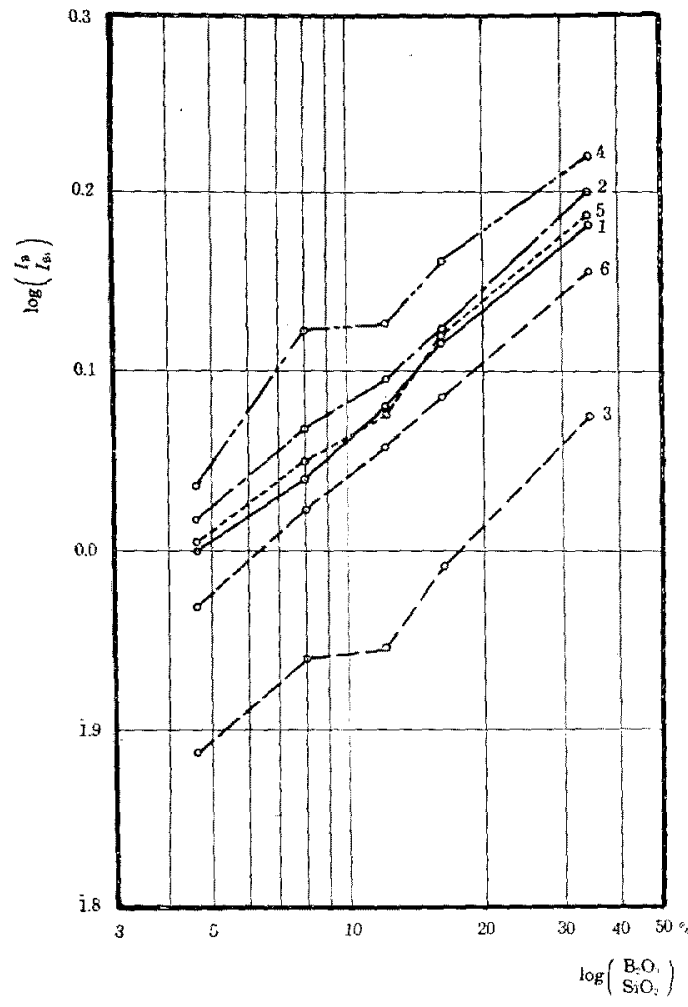

第 5 四

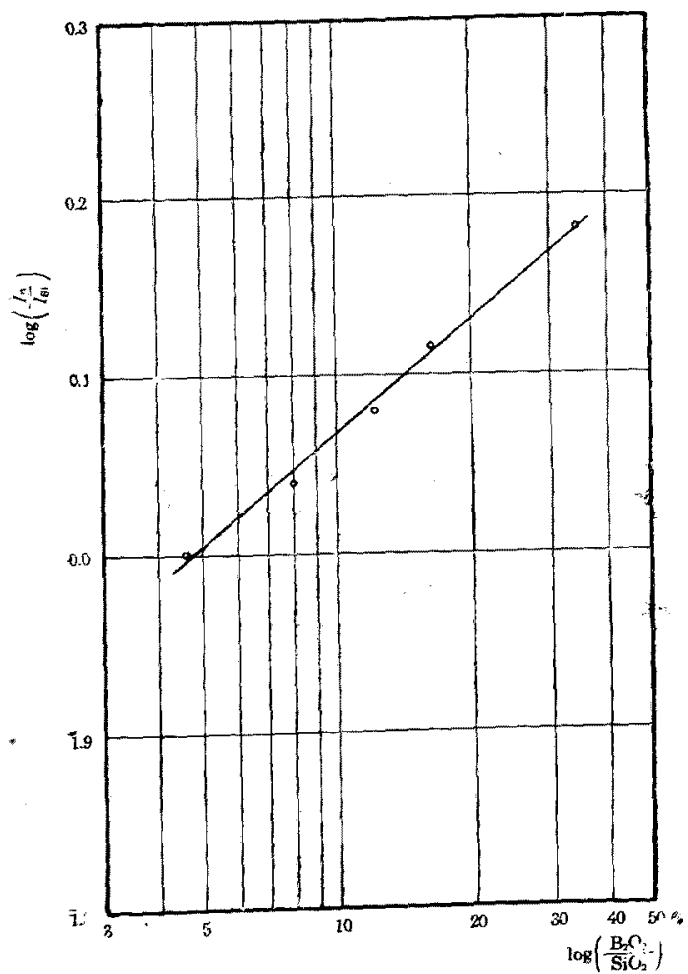

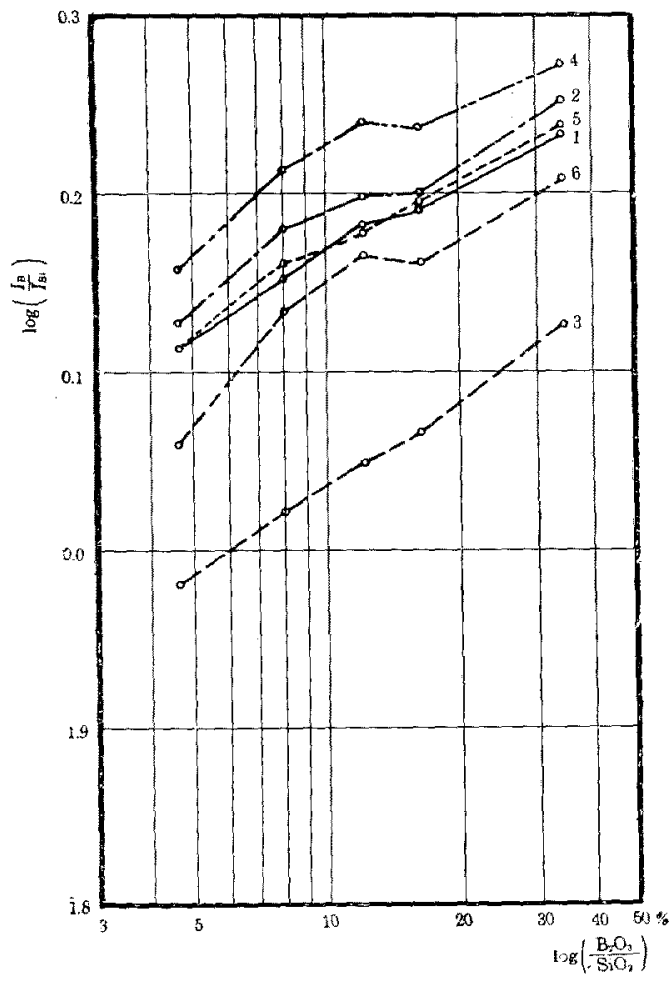

觔 6 阔

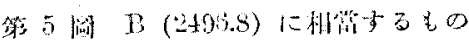

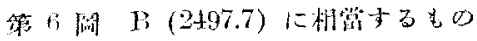

$$
\begin{array}{ll}
1 & \text { Si }(2503.9) \\
\Rightarrow & \text { Si }(2514.3) \\
8 & \text { Si }(2516.1) \\
+ & \text { Si }(2519.2) \\
5 & \text { Si }(2524.1) \\
1 & \text { Si }(2528.5)
\end{array}
$$




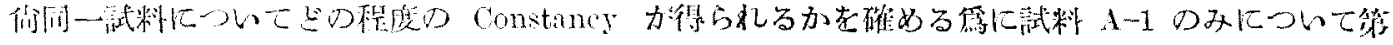
6 表の如く行つた。

\begin{tabular}{|c|c|c|c|c|c|c|c|}
\hline & 第 & 莏 & 板 & & Sis & 故 & 忟 \\
\hline 细 1 田 & 柯閶距憔 & $1.8 \mathrm{mma}$ & (j国质得撮影 & 的 1 [目] & 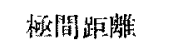 & $1.8 \mathrm{~mm}$ & 5 回反復撮题 \\
\hline 筙乥可 & 柯在取り換一 & $" \prime$ & $"$ & 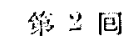 & \multicolumn{2}{|c|}{ 籍一间の䡆をとのまま } & $"$ \\
\hline 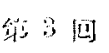 & 極を取り换一 & " & $"$ & 節润间 & \multicolumn{2}{|l|}{ 概老取り换一 } & $6[\mathrm{~L}] \prime \prime$ \\
\hline 彩; + 比 & 枢を伡り換一 & " & " & 符 4 间] & \multicolumn{2}{|l|}{ 掼老取り搰一 } & $"$ \\
\hline & \multicolumn{3}{|c|}{ （上極の苝端の丸くなつたもの使川） } & 符 5 包] & \multicolumn{2}{|l|}{ 椥老仮り换一 } & $"$ \\
\hline 笠 5 四 & \multicolumn{2}{|c|}{ 上相のみ取り换一 } & $"$ & 能6问 & \multicolumn{2}{|c|}{ 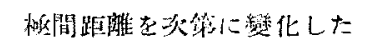 } & \\
\hline $4 ; 6[4]$ & \multicolumn{2}{|c|}{ 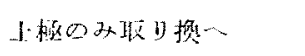 } & $"$ & & 1. 敕閶距陮 & $1.8 \mathrm{~mm}$ & \\
\hline $3 ; ; 7 \mathrm{U}]$ & \multicolumn{2}{|c|}{ 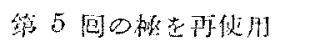 } & 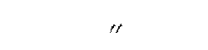 & & 2 & 1.1 & \\
\hline \multirow[t]{4}{*}{ 的末比 } & \multirow[t]{4}{*}{ 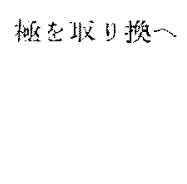 } & & $"$ & & $\because$. & 1.8 & \\
\hline & & & & & 4. & 3.0 & \\
\hline & & & & & 5 & 3.4 & \\
\hline & & & & & 6. & 4.11 & \\
\hline
\end{tabular}

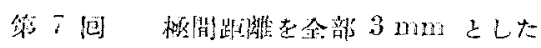

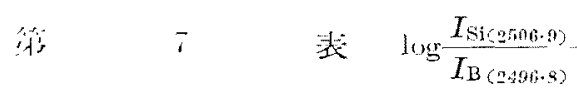

\begin{tabular}{|c|c|c|c|c|c|c|c|c|c|}
\hline 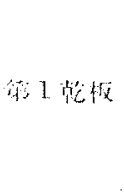 & \begin{tabular}{|}
1.000 \\
876 \\
878 \\
802 \\
$88 \%$ \\
874
\end{tabular} & $\begin{array}{l}817 \\
476 \\
920 \\
858 \\
856 \\
881\end{array}$ & $\begin{array}{l}861 \\
891 \\
87 ! \\
894 \\
64 ! \\
962\end{array}$ & $\begin{array}{l}876 \\
886 \\
895 \\
915 \\
887 \\
860\end{array}$ & $\begin{array}{l}880 \\
92 \% \\
863 \\
863 \\
898 \\
885 \\
885\end{array}$ & $\begin{array}{l}827 \\
874 \\
940 \\
975 \\
901 \\
922\end{array}$ & $\begin{array}{l}86 ? \\
886 \\
891 \\
858 \\
869 \\
868\end{array}$ & $\begin{array}{l}855 \\
928 \\
949 \\
926 \\
876 \\
871\end{array}$ & $\begin{array}{l}\text { 本均 } \\
\overline{1} .890\end{array}$ \\
\hline 和”整性 & $\begin{array}{l}1.810 \\
830 \\
890 \\
885 \\
881\end{array}$ & $\begin{array}{l}813 \\
811 \\
871 \\
845 \\
850\end{array}$ & $\begin{array}{l}\text { sis } \\
85 \% \\
674 \\
807 \\
\text { sin } \\
\text { sin }\end{array}$ & $\begin{array}{l}840 \\
419 \\
808 \\
853 \\
850 \\
883\end{array}$ & $\begin{array}{l}857 \\
851 \\
850 \\
857 \\
834 \\
836\end{array}$ & $\begin{array}{l}861 \\
838 \\
883 \\
902 \\
875 \\
874 \\
84\end{array}$ & $\begin{array}{cc}843 & \vdots \\
500 & \\
809 & \\
883 & 889 \\
881 & \vdots \\
850\end{array}$ & & 1.870 \\
\hline
\end{tabular}

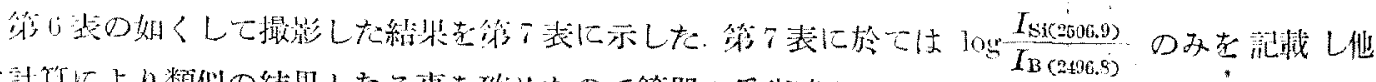

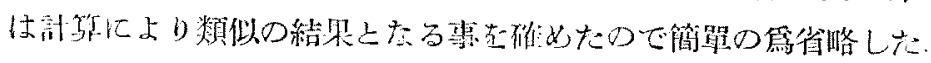

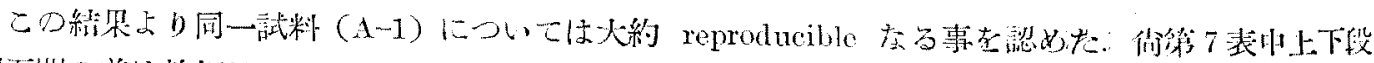

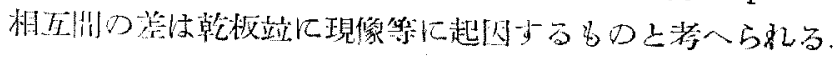

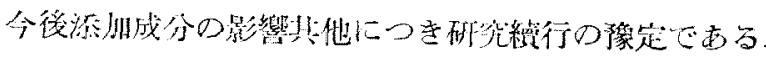

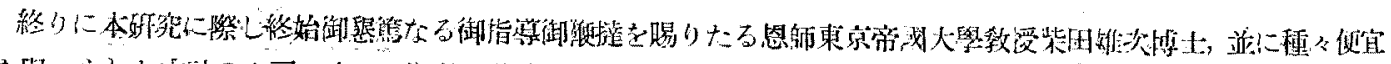

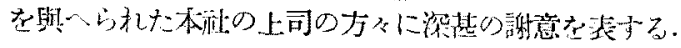

